\title{
El proyecto Sudoe
}

El proyecto "La arquitectura del siglo XX en España, Gibraltar y las regiones francesas de Aquitaine, Auvergne, Languedoc-Roussillon, Limousin, Midi-Pyrénées y PoitouCharente" fue presentado a la segunda convocatoria de propuestas de la Iniciativa Comunitaria INTERREG III B Sudoeste conjuntamente por cuatro instituciones: Fundación DOCOMOMO Ibérico, Arc-en-rêve Centre d'Architecture, Government of Cibraltar-Town Planning Section y Fundación Mies van der Rohe, a las que se sumó, en calidad de participante asociado, la Ordem dos Arquitectos de Portugal.

El objetivo genérico del denominado "proyecto Sudoe" era inventariar el patrimonio arquitectónico del siglo XX en España, Gibraltar y las regiones francesas incluidas en el "Sudoe", término utilizado por la Unión Europea para designar el ámbito territorial comprendido por la Península Ibérica y dichas regiones. Este objetivo tan sólo coincidía parcialmente con el de DOCOMOMO Internacional, ya que, desde el punto de vista temporal, extendía la investigación a todo el siglo XX y, desde el punto de vista estilístico, a fenómenos que iban más allá del denominado "Movimiento Moderno". El fin último, sin embargo, era el mismo: documentar, difundir y conservar dicha arquitectura.

Se apuntaba, por tanto, en una doble dirección: hacia el conocimiento (dirigido a la concienciación de la población y las autoridades) y hacia la intervención (dirigido a la preservación de dicho patrimonio). Los medios que se postulaban para alcanzar estos objetivos eran: una base de datos consultable desde Internet, una publicación con CDRom y una exposición.

Ahora se culmina la primera fase del proyecto, fase que comenzó con un rastreo bibliográfico que tomó el pulso al estado de la cuestión. A continuación, se puso en marcha un doble proceso: por un lado completar la información referente a territorios y espacios temporales insuficientemente cubiertos; por otro, verificar sobre el terreno esa información, que en muchos casos hubo de ser actualizada. Finalmente, se volcaron casi 6000 edificios en una base de datos consultable desde Internet (www.archxx-sudoe.es).

Para estructurar el trabajo el territorio nacional fue dividido en cinco zonas: NorteCantábrico (Galicia, Asturias, Cantabria, Castilla y León), Norte-Valle del Ebro (País Vasco, Navarra, La Rioja, Aragón), Este (Cataluña, Comunidad Valenciana, Murcia, Baleares), Centro (Madrid, Castilla-La Mancha, Extremadura) y Sur (Andalucía, Canarias, Ceuta y Melilla). Cada una de ellas contó con un coordinador regional: Fernando Agrasar Quiroga para la zona Norte-Cantábrico, Iñaki Bergera para la zona Norte-Valle del Ebro, Antonio Pizza di Nonna para la zona Este, Miguel Lasso de la Vega Zamora para la zona Centro y Carlos García Vázquez para la zona Sur. Su labor consistió en designar, organizar y dirigir un equipo de personas más amplio y, normalmente, disperso por las distintas provincias. Como ocurría con los coordinadores territoriales, muchos de ellos eran jóvenes profesores universitarios que llevaban años investigando la arquitectura del siglo XX en sus respectivos territorios. En el caso andaluz, y gracias a un convenio con el Instituto Andaluz de Patrimonio Histórico (que también ha colaborado en la financiación del proyecto), se ha adoptado el trabajo realizado para el Registro Andaluz de Arquitectura Contemporánea (RAAC).

Como decimos, en este momento se cierra una primera fase. Para la segunda queda pendiente una serie de tareas que no han podido ser abordadas en ésta. Lo hecho hasta ahora dibuja una topografía, pero no la analiza en profundidad. El desarrollo de la información facilitada en la base de datos se afrontará en la segunda fase. Previamente, será necesario hacer una selección entre los casi 6000 edificios actualmente recogidos, una labor que llevará a cabo un comité de expertos designado a tal efecto. 